\title{
A percepção da intertextualidade pelos alunos do ensino fundamental, nas aulas de Língua Portuguesa: diálogo entre poema e vídeo
}

DOI: http://dx.doi.org/10.21165/el.v49i2.2475

\section{Regislene Dias de Almeida'}

\section{Resumo}

Este artigo pretende apresentar o trabalho realizado durante as aulas de Língua Portuguesa, com alunos dos nonos anos do ensino fundamental, de uma escola municipal, no interior de São Paulo, sobre a análise da intertextualidade presente na apropriação de um texto literário para um produto audiovisual. Os objetos selecionados para o desenvolvimento do trabalho constituem-se do poema "Quadrilha", de Carlos Drummond de Andrade e do episódio homônimo, da série "Tudo o que é sólido pode derreter", dos diretores Rafael Gomes e Esmir Filho, com roteiro de Mariana Bastos. A análise se dará de forma a considerar a percepção que os alunos tiveram, ao analisar as relações entre o poema e o vídeo, numa perspectiva de texto multimodal e multissemiótico.

Palavras-chave: intertextualidade; multimodalidade; multissemiose; texto literário; texto audiovisual.

1 Universidade de São Paulo (USP), São Paulo, São Paulo, Brasil; profregislene@gmail.com; http://orcid.org/0000-0002-0713-3821 


\section{La percepción de la intertextualidad por los alumnos de enseñanza fundamental en las clases de Lengua Portuguesa: diálogo entre poema y video}

\section{Resumen}

Este artículo se propone a presentar el trabajo realizado durante las clases de Lengua Portuguesa, con alumnos del último año de la educación secundaria de una escuela municipal, en el interior de São Paulo, acerca del análisis de la intertextualidad en la apropiación de un texto literario hacia un producto audiovisual. Los objetos seleccionados para el desarrollo del trabajo son constituidos por el poema "Quadrilha", de Carlos Drummond de Andrade y del episodio homónimo de la serie "Tudo que é sólido pode derreter", de los directores Rafael Gomes y Esmir Filho, con el guión de Mariana Bastos. El análisis ocurrirá de manera a considerar la percepción que los alumnos tuvieron al analizar las relaciones del poema con el video, en una perspectiva de texto multimodal y multisemiótico.

Palabras clave: intertextualidad; multimodalidad; multisemiosis; texto literario; texto audiovisual.

\section{Introdução}

Neste artigo, apresentamos uma análise dialógica e intertextual entre um texto da esfera literária e um texto audiovisual. Trata-se do diálogo entre o poema "Quadrilha", de Carlos Drummond de Andrade e o episódio homônimo, da série "Tudo o que é sólido pode derreter", dos diretores Rafael Gomes e Esmir Filho, com roteiro de Mariana Bastos. A análise que apresentamos aqui é fruto do trabalho com alunos dos nonos anos do ensino fundamental, de uma escola do interior de São Paulo, realizada durante as aulas de Língua Portuguesa e faz parte da pesquisa de mestrado, ainda em andamento, do Programa Nacional de Mestrado Profissional em Letras - o PROFLETRAS, do qual participa a autora.

A justificativa para o desenvolvimento deste tipo de trabalho, na educação básica, mais precisamente no ensino fundamental, encontra-se na necessidade de se trabalhar com a leitura, em sala de aula, de textos de diversos gêneros e esferas comunicativas, em especial, com os gêneros digitais, tão em voga na atualidade, e ao mesmo tempo, com presença tão pouco significativa na escola. A Base Nacional Comum Curricular - BNCC -, documento que orienta o trabalho pedagógico em âmbito nacional, aponta, em vários momentos, como nas diretrizes gerais e específicas para a educação básica, para o ensino da área de linguagens e, particularmente, de Língua Portuguesa, a premente necessidade de inserção das tecnologias digitais e do trabalho com o texto, numa perspectiva multimodal e multissemiótica, nas práticas escolares. Essas práticas incluem a leitura, 
interpretação e produção de textos orais e escritos, tomando as suas diversas formas de disseminação e produção, desde a impressa até as digitais. Diante disso, temos que:

Leitura no contexto da BNCC é tomada em um sentido mais amplo, dizendo respeito não somente ao texto escrito, mas também a imagens estáticas (foto, pintura, desenho, esquema, gráfico, diagrama) ou em movimento (filmes, vídeos etc.) e ao som (música), que acompanha e cossignifica em muitos gêneros digitais. (BRASIL, BNCC, 2017, p. 68).

Ao considerar que a capacidade de leitura não se restringe somente ao texto escrito, temos que admitir que a concepção de texto, tomado como objeto de leitura, também está além dessa restrição. Quando nos referimos, então, à perspectiva multissemiótica e multimodal, empregada na análise dos textos, estamos considerando todos os fatores geradores de sentidos que os constituem e as múltiplas formas pelas quais eles se comunicam, incluindo os elementos verbais (que se utilizam da linguagem oral, escrita ou visual-motora, como Libras, por exemplo), os visuais (imagens, velocidade de projeção das imagens, enquadramentos da câmera, cores) e os sonoros (sons, músicas, entonação e velocidade da fala).

Ler, efetivamente, um texto, no entanto, não é uma habilidade nata, ou algo que se consegue apenas intuitivamente. O professor José Luiz Fiorin, em um artigo sobre a noção de texto na semiótica, apresenta a seguinte reflexão: "[...] interpretar não é dom, nem uma questão de sensibilidade. [...] é claro que um bom leitor deve ter sensibilidade. No entanto, ela não é dom divino, mas é algo que se constrói com a educação." (FIORIN, 1995, p. 171). Trazer a este artigo essa reflexão parece-nos bastante apropriado, uma vez que o que pretendemos discutir aqui são os percursos percorridos em algumas aulas de Língua Portuguesa, ao se trabalhar com a leitura e interpretação de textos literários - no caso, o poema de Drummond - e de textos audiovisuais - o episódio da série, já mencionado - sob a ótica da intertextualidade.

Para isso, apresentamos os percursos metodológicos para o desenvolvimento das atividades com os alunos, que constam da a) apresentação e leitura do poema, b) da apresentação, contextualização e exibição do episódio da série, c) dos resultados obtidos com a análise desses dois textos e d) da sistematização do conceito de intertextualidade, apresentado aos alunos ao final das discussões. Os trechos transcritos aqui são resultantes da interação entre professora-pesquisadora, alunos e objetos de estudo, cuja gravação se deu durante as aulas dedicadas ao desenvolvimento do tema da intertextualidade e da análise dos objetos apresentados.

Antes de passarmos às seções seguintes, que apresentam o corpus utilizado para o trabalho com os alunos, acreditamos ser necessário tratar da questão da intertextualidade, conceito proposto por Júlia Kristeva (1974, p. 62), na esteira de Bakhtin, segundo a qual 
"todo texto se constrói como um mosaico de citações, por absorver e transformar outros textos". Constituindo o episódio da série uma apropriação do texto literário - objetivo, aliás, de toda a série, como será mostrado mais adiante -, consideramos esta definição bastante apropriada para nortear a análise que aqui se apresenta.

Quanto aos objetos destinados à análise, consta, na primeira seção, o poema de Drummond, cuja escolha se justifica por ser um texto curto, de fácil acesso aos alunos, que dialoga com uma série que trata de interesses comuns à juventude: conflitos com a autoridade dos pais, amores platônicos, amizades e questionamentos existencialistas, comuns nessa fase da vida; na segunda seção, temos uma menção sobre a série de televisão e a descrição do episódio analisado e, na terceira, a apresentação das aulas e das análises realizadas com os alunos para, em seguida, prosseguirmos às considerações finais deste artigo.

Sobre a facilidade de acesso ao poema, pelos alunos, cabe ressaltar que nos referimos ao acesso material mesmo, que pode ser feito a partir de fotocópias, já que, muitas vezes, trabalhar com obras, na íntegra, se torna um problema nas escolas públicas, que não dispõem de exemplares em número suficiente para os estudantes e professores.

Os demais poemas citados no artigo, bem como uma letra de canção e a imagem da abertura da série, podem ser vistos ao final, nos anexos.

\section{0 poema "Quadrilha”, de Carlos Drummond de Andrade}

(01) QUADRILHA

João amava Teresa que amava Raimundo

que amava Maria que amava Joaquim que amava Lili

que não amava ninguém.

João foi para os Estados Unidos. Teresa para o convento

Raimundo morreu de desastre, Maria ficou para tia,

Joaquim suicidou-se e Lili casou com J. Pinto Fernandes

que não tinha entrado na história.

(ANDRADE, 1973, p. 19)

O poema acima, publicado em 1930, no livro Alguma Poesia, de Drummond, traz a temática dos desencontros amorosos, constante na obra do poeta mineiro. Estruturalmente, contém uma única estrofe dividida em dois momentos distintos: a situação inicial de apresentação das personagens e de seus "amores" e o destino de cada uma delas. Logo no primeiro momento, instaura-se o "desencontro", por meio de uma "pequena narrativa linear centrada em personagens sem singularidade, que vivem o drama cotidiano do desengano amoroso" (PASSOS, 2001, p. 140). A organização em orações com a mesma 
estrutura sintática - orações subordinadas adjetivas - constrói elos de significação entre as personagens, para quem o objeto direto/amoroso de uma torna-se o sujeito/ amante de outra, sem que jamais ocorra a reciprocidade. Essa cadeia é rompida somente com Lili, que destina o seu amor a "ninguém", interrompendo o fluxo dos amores sujeitoobjeto. Passos (2001) chama atenção para o único verbo transitivo do período: "amar", cuja transitividade termina com Lili, que também anuncia o que virá na sequência: orações compostas por verbos, em sua maioria, intransitivos.

O segundo momento do poema interrompe a ligação entre as personagens ao se referir ao destino de cada uma por meio de orações coordenadas assindéticas, que transmitem a noção de "ações independentes". A trajetória e sina solitária de cada uma estão postas: partida, morte, confinamento e até o estigma de "ficar para tia". Mais uma vez é Lili quem rompe com a recorrência dos acontecimentos, casando-se com J. Pinto Fernandes. Sobre essa situação, temos uma análise interessante, apresentada na citação

\begin{abstract}
[...] ela [Lili] desfaz a intransitividade, introduz a instituição "casamento" (no lugar do amor?), como também substitui o pronome "ninguém" - símbolo textual da ausência de afeto - por um nome/sobrenome que lembra razão social, remetendo a um universo de patrimônio e comércio em choque com o lírico do primeiro parágrafo. (PASSOS, 2001, p. 140).
\end{abstract}

Aos poucos, o tom eminentemente lírico do início do poema torna-se amargo e irônico. A contradança, que dá nome ao texto do poeta itabirano, apesar de ter como características a alegria e animação, prevê, em vários momentos de sua coreografia, a troca de pares, o que pode ser relacionado também com os primeiros versos do poema.

\title{
0 episódio "Quadrilha”, da série "Tudo o que é sólido pode derreter"
}

A série "Tudo o que é sólido pode derreter", produzida em 2008 pela Ioiô Filmes, em parceria com a TV Cultura, e veiculada pela emissora durante o ano de 2009, conta com 13 episódios que dialogam com diversos clássicos da literatura. De autoria dos diretores e roteiristas brasileiros Rafael Gomes e Esmir Filho, aborda, de maneira descontraída, os conflitos vividos por um grupo de adolescentes, tendo como pano de fundo o ambiente escolar, as aulas de Literatura e os livros lidos pela personagem principal, Thereza.

Foi criada a partir de um premiado curta-metragem dirigido por Rafael Gomes, que teve o mesmo nome da série. Nele, a personagem principal, uma garota de 15 anos, tem que estudar a peça Hamlet, de Shakespeare, justamente numa fase em que sua vida está em crise. O filme expõe a solidão e a angústia características da adolescência, a rotina escolar e a dor da perda de um ente querido - tudo permeado pela descoberta de um clássico da literatura universal. Vencedor de diversos prêmios de importantes festivais infanto-juvenis, como o Oberhausen, na Alemanha, o curta inspirou a série, que se dedicou às obras literárias de língua portuguesa. 
De acordo com a matéria de Léo Lima, Mariana Meyer, Daiana Sigiliano e Vinícius Guida (2018), no site "Observatório da qualidade no audiovisual" - que é um espaço de diálogo sobre a produção audiovisual contemporânea e integra o Grupo de Pesquisa Comunicação, Arte e Literacia Midiática da Universidade Federal de Juiz de Fora (UFJF) -, após o encerramento da primeira temporada na TV Cultura, em 2009, ainda foram lançados conteúdos referentes ao universo ficcional. Em 2010, foi lançado o box com todos os episódios da série, making off e quatro e-books. Em 2011, Rafael Gomes lançou uma versão adaptada dos episódios da TV, em livro que, editado pela Leya, mantém as mesmas histórias da trama da TV Cultura, com pequenas mudanças por conta do formato.

Ainda de acordo com o site, "anos depois da sua transmissão original, o conteúdo ainda circula pela internet. Disponibilizada pela produtora, atualmente nomeada Intro Pictures, a playlist da série atualmente conta com 10 mil visualizações." (LIMA; MEYER; SIGLIANO; GUIDA, 2018).

Situar, dentro da série, o episódio que abordamos neste artigo, torna-se importante ao considerá-lo numa perspectiva bakhtiniana, ou seja, como um discurso produzido numa determinada esfera de atividade humana, cujos sentidos são construídos a partir de todos os elementos relacionados a sua produção (BAKHTIN, 1997). Isso implica dizer que a ordem de exibição dos episódios e onde, nessa sequência, o episódio que estudamos se encaixa, é também um fator gerador de sentidos, que deve ser levado em conta na sua interpretação. Apresentamos, então, a lista dos episódios produzidos, na mesma ordem em que foram exibidos, cujos títulos são homônimos às obras de referência:

(02) 1. Auto da Barca do Inferno, de Gil Vicente;

2. Os Sermões, de Padre Antônio Vieira;

3. Os Lusíadas, de Luís Vaz de Camões;

4. Canção do Exílio, de Gonçalves Dias;

5. Senhora, de José de Alencar;

6. Macário, de Álvares de Azevedo;

7. Dom Casmurro, de Machado de Assis;

8. Ismália, de Alphonsus de Guimarães;

9. Quadrilha, de Carlos Drummond de Andrade;

10. Uma Aprendizagem ou o Livro dos Prazeres, de Clarice Lispector;

11. Quem casa quer casa, de Martins Pena;

12. O Guardador de Rebanhos, de Fernando Pessoa;

13. Macunaíma, de Mário de Andrade.

Os episódios da série ambientam-se numa escola pública da cidade de São Paulo e têm como personagens principais Thereza, a protagonista, Marcos e Letícia, seus melhores amigos, João Felipe, por quem a protagonista se apaixona, e Dalila, a antagonista, rival de 
Thereza. Além dessas, há outras personagens fixas na história, como os demais colegas da turma, em destaque Igor (que traz o estereótipo do aluno "nerd") e Beto (que se envolve amorosamente com Letícia, a melhor amiga de Thereza), o professor de Literatura, os pais de Thereza (Marta e Décio) e o tio Augusto, que desempenha importante papel ao discutir com sua sobrinha - a personagem principal - questões existenciais e filosóficas.

O episódio que será apresentado aos alunos é o nono na ordem da série, com duração aproximada de 25 minutos. Tem como mote o aniversário de 15 anos de Thereza, que acontece no mesmo dia em que ocorre uma excursão escolar para um acampamento, onde iriam comemorar a festa junina. Na narrativa, os alunos se reúnem no pátio da escola, ponto de partida para a viagem, e Marcos, amigo de Thereza, dando-lhe os parabéns, revela que gostaria de lhe presentear com algo que fosse inesquecível. Já no ônibus, a caminho do acampamento, Thereza encontra um bilhete anônimo dentro de sua bolsa, com o poema "Poesia", de Drummond. Então, pergunta a Marcos, que está sentado ao seu lado, ainda meio sonolento, quem ele acha que poderia ter the mandado o recado. A partir daí, Thereza tenta reunir pistas que revelem a identidade do autor do bilhete, que é tomado como uma possível declaração de amor.

Em meio às atividades do acampamento, cenas em flashback são inseridas na narrativa para apresentar ao espectador as investigações de Thereza, na busca por quem Ihe enviara o bilhete. Nessas cenas, ela dialoga com Marcos, que sempre refuta suas suspeitas, e com o tio Augusto, que tenta Ihe encorajar na descoberta dos seus sentimentos amorosos. Nos flashbacks, Thereza aponta a autoria do poema escrito no bilhete como uma prova de que quem o enviou seria conhecedor do poeta, Carlos Drummond de Andrade. Esse fato direciona suas suspeitas a Marcos, que prontamente identificou o autor do poema pertencendo à literatura modernista.

No tempo linear da narrativa, os alunos participam de brincadeiras no acampamento, ocupam-se na piscina e em jogos esportivos e fazem a decoração da festa junina. Pares amorosos vão se formando entre os alunos e Dalila, a antagonista, empenhada em conquistar o monitor do acampamento, despreza Igor, sempre que este lhe dirige as atenções. Nesse contexto, João Felipe tenta, por diversas vezes, revelar algo a Thereza, mas sempreé interrompido pelo monitor do acampamento ou por Dalila, com quemjá tivera um relacionamento amoroso, em episódios anteriores. Numa das brincadeiras propostas pelo monitor, as personagens estão em uma mata escura, parte do acampamento, participando do jogo "Pega Bandeira" e Thereza ouve uma voz desconhecida declamando as estrofes finais de "Lira Romantiquinha", também de Drummond. Amedrontada, porém curiosa, ela conta o ocorrido a João Felipe, que the revela que também encontrou um bilhete anônimo em sua mochila.

O clímax da narrativa ocorre numa noite, quando Thereza procura por João Felipe, em seu alojamento, e eles ouvem a mesma "voz desconhecida" declamando a "Lira Romantiquinha". Ao se dirigirem à janela do quarto, avistam Marcos, utilizando uma 
cartolina em formato cilíndrico para disfarçar a voz e declamando o poema. Thereza e João Felipe decepcionam-se ao descobrir que o amigo era o autor dos acontecimentos e pedem-Ihe explicações. Marcos se esquiva, inventando mentiras que não convencem os colegas e promete explicar-Ihes tudo no dia seguinte.

O desfecho da história se dá nas próximas cenas, com a última grande noite da turma no acampamento e a tão esperada festa junina. Na festa, em meio a brincadeiras, músicas e danças típicas, casais que estavam juntos se desfazem e formam-se outros, como na quadrilha. Igor, colega responsável pelo correio elegante, entrega bilhetes de Marcos a João e Thereza, combinando um local de encontro. Chegando ao local combinado - em meio a árvores do acampamento -, João e Thereza se veem sozinhos e concluem que Marcos não comparecerá. João vê uma caixa de presente presa em uma árvore, com um cartão endereçado a Thereza, contendo os seguintes dizeres: "Thereza, o Drummond escrevia sobre amor, mas também sobre amizade, esse é o meu presente inesquecível pra você, e só para não deixar sem o último poema, aqui vai o começo de "Quadrilha": "João amava Thereza". Feliz aniversário!" (GOMES; FILHO, 2008, DVD 3, 22'27"-22'42").

A leitura silenciosa do cartão, feita pela personagem, com a utilização da voz de Marcos para a narração, é a deixa para que João Felipe Ihe declare o seu amor e terminem o episódio com um beijo romântico, acompanhado pela canção "Mesmo quando a boca cala", de Vinícius Calderoni.

Finda-se, assim, o episódio de nossa análise.

\section{Diálogo entre o poema e o vídeo: as relações intertextuais exploradas com os alunos}

Ao iniciar a apresentação da análise feita, acerca dos objetos apresentados, esclarecemos a forma de apresentação desses objetos aos alunos. O poema de Drummond foi fotocopiado, a partir do exemplar do livro "Alguma Poesia", e as cópias foram entregues aos alunos, individualmente. O episódio da série foi exibido na sala de informática, em uma TV ligada à internet, por meio do acesso ao vídeo disponibilizado pelo YouTube. Para esta etapa da atividade, foram necessárias duas aulas: uma para o diálogo sobre o poema, levantamento de conhecimentos prévios sobre o autor e outras de suas obras e mais uma para a exibição do episódio e estabelecimento de relações entre os textos.

Sobre o conhecimento dos alunos acerca dos objetos em estudo, alguns mencionaram conhecer o poema apresentado, ou terem tido contato com ele em algum momento da vida escolar. Em relação à série, pouquíssimos - dois ou três alunos, de setenta e cinco, aproximadamente - conheciam. Então, antes da exibição, foi necessário contextualizar o episódio, dentro da série, apresentando as personagens principais e o objetivo do programa, que é justamente promover a aproximação do público juvenil com algumas obras clássicas da literatura. 
Nesta análise, para facilitar as referências aos textos, designamos por Texto 1 (T1) o poema "Quadrilha", de Drummond, e Texto 2 (T2) o episódio da série. Após lermos o $\mathrm{T} 1$, a temática dos desencontros amorosos, ou dos amores não correspondidos, como disseram os alunos, foi prontamente identificada como sendo o assunto principal do poema. Alguns alunos mencionaram a morte e o suicídio como temas principais e a nossa intervenção se deu no sentido de entenderem que a decepção amorosa ocorre com praticamente todas as personagens do poema, enquanto a morte por desastre e o suicídio se configuram como o destino de apenas duas personagens. Sobre o T1, o que Ihes chamou bastante atenção foi o destino de Lili, sendo a única personagem que "não amava ninguém" e a única que teve um "final feliz" - sem desastres, solidão ou morte.

As respostas ao questionamento básico de por que só "J. Pinto Fernandes" aparece com sobrenome, na história do $T 1$, foi diretamente relacionada à possível riqueza da personagem. Posse de bens materiais, status social e luxo foram predicados atribuídos pelos alunos a ele. Na sequência da análise, atentamos para o fato de Lili, possivelmente, ter se casado com um homem rico e o fato de ela "não amar ninguém" ter uma conotação mais positiva do que negativa, aos olhos dos alunos, pois, num mundo regado a desastres amorosos, aqueles que se abstêm do amor têm alguma vantagem.

Dadas as considerações sobre o T1, passamos à relação entre os dois textos, cuja primeira associação a ser feita é a da temática: o desencontro amoroso no T1 e os encontros/ desencontros no T2. Enquanto um sujeito se configura como o objeto do amor do outro, no T1, temos no T2 encontros que se concretizam com maior facilidade, na formação dos pares amorosos pelas personagens secundárias da trama e pela situação final das personagens principais. Já os desencontros aparecem na fugacidade com que esses pares são desfeitos. O nome das personagens do T2, ao coincidir com o das personagens dos versos iniciais do T1, corrobora a interligação estabelecida na apropriação do poema pelo vídeo, presente também na ambientação da narrativa. O espaço do acampamento escolar e a realização da festa junina relacionam-se com o título de ambos os textos, que, como mencionado, remete à contradança típica das festividades de junho.

Mais uma associação possível é a da personagem Dalila (T2), que desempenha um papel semelhante ao de Lili ( $\mathrm{T} 1$ ), ao realizar constantes quebras no fluxo dos acontecimentos, como as frequentes interrupções que fazia ao par romântico, Thereza e João. A semelhança acentua-se ainda mais quando Dalila volta seus interesses para o monitor do acampamento, personagem esporádica na série, fora do contexto escolar, que pode ser tido como "alguém que não tinha entrado na história"...

A presença de outros poemas e versos de Drummond no T2 amplia a inserção do poeta na narrativa, cujas cenas em flashback, nas quais se discute a autoria do poema recebido de forma anônima pela personagem, cumprem um dos objetivos da série, que é a aproximação de obras clássicas da literatura luso-brasileira com o cotidiano dos jovens. 
Obviamente, ao elencar esses elementos, temos algumas relações de intertextualidade já estabelecidas, uma vez que o T2, por diversas vezes, recupera e subverte elementos enunciados no T1.

Para trazer à discussão as análises feitas com os alunos, nesse viés comparatista, reproduzimos alguns diálogos com os alunos da turma, obtidos com a gravação das aulas, visando demonstrar como se deram os movimentos interpretativos dos textos, até chegarmos à sistematização do conceito de intertextualidade. Os nomes dos alunos participantes da conversa foram suprimidos ou representados por iniciais, de modo a preservar suas identidades.

À primeira vista, as percepções dos alunos centraram-se na cenografia do episódio e aos nomes das personagens: a realização da festa junina e a dança quadrilha, como se vê neste primeiro exemplo:

(03) (professora) - E aí, turma, o que têm em comum o poema que lemos na aula anterior com o episódio da série [sic] que acabamos de assistir?

(aluna 1) - Os dois fala [sic] de festa junina, professora, de quadrilha... da dança.

(aluno 2) - O nome, os dois chama [sic] Quadrilha...

(professora) - E o que mais vocês conseguiram perceber de parecido?

(aluno 3) - Os nomes do João e da Thereza, que é como começa a poesia.

(aluna 4) - Ah, e que aquela menina gostava do cara e ele não gostava dela...

(professora) - Quem são a menina e o cara, consegue me dizer, V.?

(aluna 5) - Ah, o carinha do acampamento e aquela que se acha... Dalila, né?...

Nesse diálogo, ficam evidentes duas percepções: a da constituição do espaço da narrativa, como já dissemos, e a relação dos amores não correspondidos, tema central do poema de Drummond. Na sequência da conversa sobre o texto, foi apontada por uma aluna a questão dos demais pares que se formaram na história, o que se deu da seguinte maneira:

(04) (aluna 1) - Mas, professora, todo mundo um ficou com o outro... assim... da sala, da turma deles. Só a Dalila que queria ficar com o cara mais velho, o do acampamento.

(aluna 2) - Tudo bem que o carinha era bonitinho... dava pra pegar!

(risadas gerais)

(aluna 1) - Mas não era da turma. Por que só ela quis ficar com ele? 
(professora) - Interessantíssima essa questão, M.E.! Vocês conseguem relacionar isso com o poema também? Acham que tem um motivo para isso ter aparecido no vídeo?

(aluno 3) - Não. Porque o vídeo não tem tudo o que tem no poema.

(professora) - O quê, por exemplo, você acha que tem no poema e faltou no vídeo?

(aluno 3) - Ninguém morre, ninguém se suicida, professora! Ficou chato...

(aluno 4) - É, na poesia um morreu de acidente e o outro se suicidou, lembra professora.

(professora) - Sim, lembro. E por que vocês acham que não colocaram isso no vídeo?

(aluno 5) - Por que é para adolescente?

(professora) - Hum... não sei... pode ser. Mas eu reforço o convite para vocês assistirem os outros episódios da série. Talvez vocês mudem de opinião sobre isso.

Interrompemos a reprodução dos diálogos, nesse ponto, para apontar que a percepção do que faltou no vídeo, ao se apropriar do poema, segundo os alunos, é fundamental no movimento de análise intertextual. A apropriação de um texto para outro produto não requer que todos os seus elementos estejam presentes no novo objeto. A relação de intertextualidade pode se dar, apenas, por referências ao texto de origem, por exemplo.

Embora nossa análise esteja centrada nas relações intertextuais, não podemos deixar de fora as relações intermidiáticas que circundam a apropriação do texto literário para o produto audiovisual. "As características da mídia pela qual o enunciado é veiculado são determinantes para o conjunto de elementos que constituem as coerções genéricas" (CARETTA, 2013, p. 103). Isso significa que essas formas de dizer, próprias do audiovisual, requerem modelos de enunciados também próprios que, muitas vezes, não abarcam todos os elementos constitutivos do texto no qual se baseia.

Nesse movimento interpretativo, cabe ainda uma reflexão sobre algumas considerações dos alunos frente ao poema de Drummond: em mais de uma sala, como já disse anteriormente, ao perguntar sobre de que tratava o poema, obtive respostas como morte e suicídio. Interessante pensarmos sobre o porquê de esses assuntos ganharem evidência às vistas dos alunos, mesmo sendo secundários no poema. O fato de mais de um aluno considerar chato o episódio porque não aparecem mortes também revela um ponto interessante a ser analisado. Obviamente, esta discussão não será feita aqui, mas é importante refletir sobre ela, quem sabe, num próximo artigo.

Antes de passarmos à continuidade da análise, justificamos nosso convite aos alunos para que assistam aos outros episódios da série, que além de ser um estímulo para que tenham contato, de forma prazerosa, com outras apropriações literárias para vídeo, se deu pelo fato de, em alguns episódios, tratar da temática do suicídio, relacionada a uma paciente da mãe de Thereza, que é psicóloga, e à morte do tio Augusto, que se suicida. 
Continuando nossa conversa de sala de aula, insistimos na questão do interesse de Dalila pelo monitor do acampamento, sabendo que essa questão aponta para uma interpretação menos explícita, mas intencionalmente explorada pelos idealizadores do episódio.

(05) (professora) - Então, gente, voltamos a pensar na Dalila e no monitor do acampamento. Além de ele ser bonitinho, como vocês disseram, o que mais pode ter contribuído para isso aparecer no filme, dessa forma?

(aluna 6) - Professora, na poesia não tem aquela mulher interesseira, que casa com um cara que ninguém nunca viu? Então, não pode ser ela?

(professora) - Você está falando da Lili? O que vocês acham do que a M. J. falou?

Concordam ou não com ela?

Muitos alunos concordaram com a análise da colega, que levantou mais um aspecto, bastante importante, da relação entre o poema e o vídeo apresentado. Sobre as cenas em flashback, em que estão inseridas informações sobre o autor do poema e sobre suas outras produções, contidas no episódio, os alunos acreditaram que "era para saber mais sobre o Carlos Drummond", análise, a nosso ver, coerente com a maturidade dos alunos com quem trabalhamos.

A partir dessa análise nós pudemos, no prosseguimento das aulas, sistematizar com os alunos o conceito de intertextualidade, levando em conta as relações dialógicas propostas por Bakhtin (1997), Kristeva (1974) e por outros teóricos, que consideram as várias vozes que perpassam os enunciados, na sua constituição. Ficou evidente que a relação estabelecida entre textos - que tem o seu grau de explicitude bastante variável ultrapassa os limites do gênero, podendo se apresentar em diversos suportes e mídias, por meio de um ou de vários outros gêneros, ampliando, para além das relações intertextuais, relações multimodais e multissemióticas, vistas nas várias produções artístico-culturais da atualidade.

Para encerrar, vale dizer que na continuidade das aulas muitos alunos demonstraram interesse em assistir à série toda. O endereço dos vídeos foi disponibilizado a eles e esperamos que o interesse se volte também às obras literárias de que tratam os episódios. A música final do episódio também foi objeto de interesse de algumas alunas, que perguntaram sobre sua autoria.

\section{Considerações finais}

Acreditamos que esta análise dialógica e mediada, de dois textos de diferentes suportes e mídias, possa oferecer aos alunos subsídios para que realizem interpretações de outros produtos artístico-culturais, de circulações midiáticas diversas, sendo capazes de 
estabelecer relações mentais complexas, como a comparação, relação e apropriação, e de considerar as várias vozes presentes nas relações intertextuais.

Mais uma vez, reafirmamos a necessidade de se trabalhar, na escola, com textos oriundos de diversas mídias, principalmente das digitais, de forma a estreitar as relações entre o ambiente escolar e o mundo real, pois a contemporaneidade requer pessoas com habilidades para operar sobre esse espaço de mudanças e novidades tecnológicas.

Esperamos, ainda, que esse exercício de compreensão do processo de apropriação dos textos literários para produtos audiovisuais torne-se um fator de motivação para que os alunos possam pensar em criar os seus próprios produtos digitais, superando a condição de meros consumidores de tecnologia digital para desenvolvedores de projetos autorais.

\section{REFERÊNCIAS}

ANDRADE, C. D. de. Alguma poesia. In: ANDRADE, C. D. de. Reunião. Rio de Janeiro: José Olympio, 1973.

ANDRADE, C. D. de. Antologia poética de Carlos Drummond de Andrade (e-book Kindle). São Paulo: Companhia das Letras, 2012.

BAKHTIN, M. M. Estética da criação verbal. Tradução Maria Ermantina Galvão. 2. ed. São Paulo: Martins Fontes, 1997.

BRASIL. Base Nacional Comum Curricular (BNCC). Brasília, MEC/ CONSED/ UNDIME, 2017. Disponível em: www.basenacionalcomum.mec.gov.br/. Acesso em: 31 mar. 2019.

CALDERONI, V. Letras. Disponível em: https://www.letras.mus.br/5-seco/1763295/ mesmo-quando-a-boca-cala-print.html. Acesso em: 27 ago. 19.

CARETTA, Á. A. Estudo dialógico-discursivo da canção popular brasileira. São Paulo: Annablume, 2013.

FIORIN, J. L. A noção de texto na semiótica. Revista Organon, v. 9, n. 23, 1995. Disponível em: https://bit.ly/3gneQNr. Acesso em: 10 jul. 2019.

GOMES, R.; FILHO, E. Tudo o que é sólido pode derreter. São Paulo: Cultura - Fundação Padre Anchieta, 2008. 4 DVDs (344 min.). Episódio "Quadrilha", DVD 3 (25 min.). 
KRISTEVA, J. Introdução à semanálise. São Paulo: Perspectiva, 1974.

LIMA, L.; MEYER, M.; SIGLIANO, D.; GUIDA, V. Tudo o que é sólido pode derreter. Observatório da qualidade no audiovisual. 2018. Disponível em: https://bit.ly/2M25adm. Acesso em: 12 jul. 19.

PASSOS, C. R. P. De quadrilha em quadrilha: Drummond em Chico Buarque de Hollanda. In: BOSI, V. et al. O poema, leitores e leitura. Cotia: Ateliê Editorial, 2001. p. 139-152.

\section{ANEXOS}

A. Poema "Poesia", de Carlos Drummond de Andrade, presente no episódio "Quadrilha" da série "Tudo o que é sólido pode derreter"

Gastei uma hora pensando em um verso

que a pena não quer escrever.

No entanto ele está cá dentro

inquieto, vivo.

Ele está cá dentro

e não quer sair.

Mas a poesia deste momento

inunda minha vida inteira.

(ANDRADE, 2012, n.p.)

B. Trecho do poema "Lira Romantiquinha", de Carlos Drummond de Andrade, presente no episódio "Quadrilha" da série "Tudo o que é sólido pode derreter"
Acaso ignoras
que te amo tanto,
todas as horas,
já nem sei quanto?
Visto que em suma
é todo teu,
de mais nenhuma,
o peito meu?
Anjo sem fé
nas minhas juras,
porque é que é
que me angusturas? 
Minh'alma chove

frio, tristinho.

Não te comove

este versinho?

(ANDRADE, 2012, n. p.)

C. Letra da canção "Mesmo quando a boca cala", de Vinícius Calderoni, presente no episódio "Quadrilha" da série "Tudo o que é sólido pode derreter"

Foi você me olhar de lado

E eu, ao lado, doido para

Confessar

Mesmo quando a boca cala o

Corpo quer falar

Esses gestos incompletos

Olhos tão repletos de te desejar

$O$ direito de ir e vir

O desejo de ficar

Tudo isso pra dizer

Que eu não sei dizer

Onde é que isso vai dar

Que eu não mando no querer

Aliás é o querer que quer me governar

Hoje eu vivo pra dizer

- Ou digo pra viver-

Você é meu lugar

Se o amor não nos quiser

Então azar do amor:

Não soube nos amar

(Disponível em: https://bit.ly/2M2aYmY. Acesso em: 27 ago. 2019)

D. Quadro da apresentação da série "Tudo o que é sólido pode derreter", com a personagem principal, Thereza. 
Figura 1. Abertura da série "Tudo o que é sólido pode derreter"

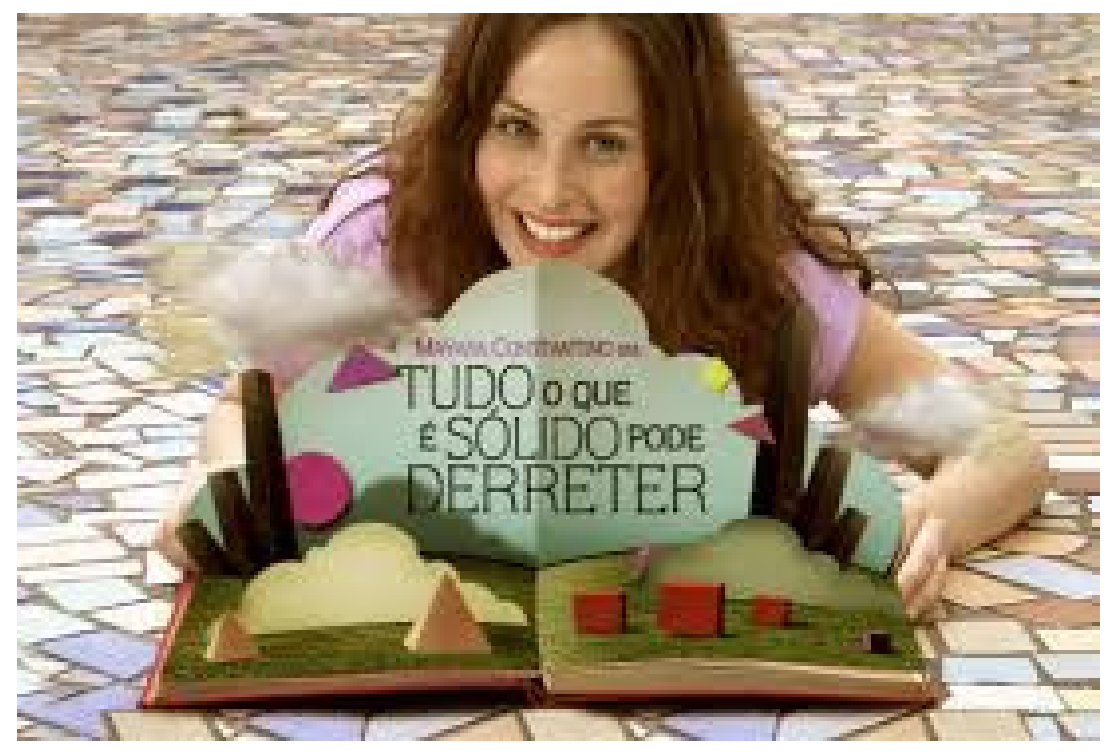

Fonte: https://bit.ly/2ZE1Mxm 